\title{
Spatial Dynamics of Two Host-Parasite Relationships on Intertidal Oyster Reefs
}

\author{
Marc H. Hanke ${ }^{1,2, * \mathbb{D}}$, Martin H. Posey ${ }^{1}$ and Troy D. Alphin ${ }^{1}$ \\ 1 Department of Biology and Marine Biology, University of North Carolina Wilmington, \\ Wilmington, NC 28403, USA; poseym@uncw.edu (M.H.P.); alphint@uncw.edu (T.D.A.) \\ 2 Honors College, University of Houston, Houston, TX 77204, USA \\ * Correspondence: marc.h.hanke@gmail.com
}

Citation: Hanke, M.H.; Posey, M.H.; Alphin, T.D. Spatial Dynamics of Two Host-Parasite Relationships on Intertidal Oyster Reefs. Diversity 2021, 13, 260. https://doi.org/10.3390/ d13060260

Academic Editors: Bert W. Hoeksema, Mark S. Peterson and Michael J. Andres

Received: 28 April 2021

Accepted: 8 June 2021

Published: 10 June 2021

Publisher's Note: MDPI stays neutral with regard to jurisdictional claims in published maps and institutional affiliations.

Copyright: (c) 2021 by the authors. Licensee MDPI, Basel, Switzerland. This article is an open access article distributed under the terms and conditions of the Creative Commons Attribution (CC BY) license (https:/ / creativecommons.org/licenses/by/ $4.0 /)$.

\begin{abstract}
Intertidal reefs comprised of the eastern oyster (Crassostrea virginica) have long experienced habitat loss, altering habitat patch characteristics of size and distance from edge to interior, potentially influencing spatial dynamics of host-parasite relationships. Using two parasitic relationships, one between eastern oyster host and parasitic oyster pea crab (Zaops ostreum) and the other between a xanthid crab (Eurypanopeus depressus) and a parasitic rhizocephalan barnacle (Loxothylacus panopaei), we examined how host-parasite population characteristics varied on intertidal reefs by season, reef size, and distance from edge to interior. Pea crab prevalence was more related to habitat characteristics rather than host density, as pea crab prevalence was the highest on large reefs and along edges, areas of comparatively lower oyster densities. Reef size did not influence densities of parasitized or non-parasitized xanthid crabs, but densities varied from edge to interior. Nonparasitized xanthids had significantly lower densities along the reef edge compared to more interior reef locations, while parasitized xanthid crabs had no significant edge to interior pattern. Organismal size had a varied relationship based upon habitat characteristics, as pea crab carapace width (CW) varied interactively with season and reef size, whereas CW of parasitized/non-parasitized xanthid crabs varied significantly between edge and interior locations. These results demonstrated that influential habitat characteristics, such as patch size and edge versus interior, are both highly species and host-parasite specific. Therefore, continued habitat alteration and fragmentation of critical marine habitats may further impact spatial dynamics of host-parasite relationships.
\end{abstract}

Keywords: Crassostrea virginica; intertidal reefs; habitat fragmentation; patch size; edge effects; host-parasite; Eurypanopeus depressus; Zaops ostreum; Loxothylacus panopaei

\section{Introduction}

The heterogeneity and spatial configuration of habitat patches within a landscape can strongly influence biodiversity at multiple scales [1-4]. Over time, habitat patches within a landscape can become fragmented either through natural or anthropogenic forces, reducing patch size and altering edge to interior ratios $[5,6]$. The alteration of these habitat characteristics can impact species interactions, often due to altered intra-patch densities and distributions [1,7-10] and may be particularly important for host-parasite relationships [11-13]. In various terrestrial systems, habitat patch size can spatially structure the interaction between parasites and their hosts through density dependent responses [14-17], patch size thresholds [12,18,19], and arrangement within the landscape [13,20-22]. However, alterations to habitat patch size can also have limited impacts on host-parasite dynamics within terrestrial habitats due to dilution effects, host sharing, and dynamic host population thresholds for parasites $[23,24]$. Variations in habitat patch size can structure the relative amount of edge to interior habitat and edge effects can be highly influential in host-parasite interactions. For example, parasitism rates have been found to be greater along habitat edges in different terrestrial habitats [25-27] or, conversely, greater within 
interior patch locations due to hosts avoiding edges [11]. The majority of the research on the spatial dynamics of parasitic interactions within habitat patches has focused on terrestrial systems $[11,27,28]$ and is largely overlooked within marine habitat types [29]. For example, in a recent review, Peterson and Andres [30] highlighted how most parasites within coastal aquatic habitats are only given attention when they are problematic and the ecological implications, at varied hierarchal levels, are often ignored.

Intertidal reefs created by the eastern oyster (Crassostrea virginica) are naturally heterogeneous and provide complex, structured habitat for a diverse community comprised of epifauna, crustaceans, and mobile nekton in a landscape that is generally unstructured substrate [31-34]. The natural heterogeneity of intertidal reefs provides diverse habitat patch sizes and, consequentially varying ratios of edge to interior habitat, which can influence oyster populations and reef associated fauna $[35,36]$. Further, oyster populations have declined due to overharvesting, eutrophication, habitat loss, disturbances, and disease, which exacerbates reef loss and fragmentation [37-39]. The decline of oysters has led to increased reef patchiness, decreased reef size, and altered edge to interior ratios $[35,40-43]$. These changes in habitat characteristics have influenced various aspects of oyster population characteristics including densities, survivorship, physiological health, and recruitment [35]. In turn, both reef size and relative amount of edge to interior is important for associated species' distribution and interactions on oyster reefs [36,40,42-44], yet how these landscape factors influence host-parasite relationships on intertidal oyster reefs remains relatively unknown. Therefore, the overall goal of this study was to determine spatial dynamics between two different host-parasite relationships to understand how varied habitat characteristics can further influence host-parasite interactions.

The first host-parasite relationship examined was between the eastern oyster and the oyster pea crab (Zaops ostreum). Pea crabs parasitize oysters from intertidal and subtidal habitats ranging from Massachusetts, USA through Brazil [45,46], but have been found in other bivalve hosts [47]. Adult female pea crabs, which have an approximate carapace width range of $4-15 \mathrm{~mm}$, live within the mantle cavity of oysters, thought to live approximately 2-3 years, and damage oyster gills during feeding [45,46,48,49]. This all can lead to lowered oyster condition (a relative measure of physiological health), meat quantity for commercial purposes, and suppressed gonadal development [45-49]. The oyster-pea crab relationship provides a unique opportunity to understand how a marine host-parasite relationship is influenced by varied habitat characteristics, as both oysters and female pea crabs are sessile after settlement. Pea crab infection rates are driven by local factors [50], and may have implications for oyster populations already stressed and in decline from other factors. For example, intertidal oysters have lowered condition along reef edges [35] and pea crabs parasitizing hosts found within this microhabitat may further reduce oyster condition $[47,49]$.

The second host-parasite relationship examined was between the flatback mud crab (Eurypanopeus depressus), and a parasitic rhizocephalan barnacle (Loxothylacus panopaei). This rhizocephalan barnacle, which is introduced to the Atlantic Coast of the United States, settles on a recently molted crab, metamorphoses and penetrates the host, and then produces a system of branching roots that damages the crabs endocrine and nervous systems, and influences host behavior [51-56]. The branching root system ultimately emerges as an externae that prevents molting and mimics the host's egg mass, which causes castration of female crabs and sterilization and feminization of males [51,52,57,58]. The flatback mud crab (henceforth referred to as xanthid crab) is an ecologically important mid-trophic level carnivore that utilizes the complex structure provided by intertidal reefs as foraging habitat to feed on oyster spat and reef-associated mussels [59-61]. Further, this xanthid crab species has a strong association with increased reef complexity [61], which often varies spatially within an intertidal reef [35], as predator refuge since they are preyed upon by larger predators such as blue crabs (Callinectes sapidus) and oyster toadfish (Opsanus tau) [62-65]. This example of host parasite relationship was included in this study because xanthid crabs are reef residents with some vagility within the habitat and because 
rhizocephalans are becoming more prevalent in their introduced range, all while xanthid crab habitat has been lost and fragmented $[39,57,60,66]$. Lastly, this host-parasite was also chosen to assess the spatial dynamics based on varied habitat characteristics because this species of xanthid have lower densities along edges of intertidal reefs compared to more interior locations [36]. Parasitic interactions are generally known to be greater along habitat edges $[11,26,27,67]$, which could potentially increase the risk of parasitism for xanthid crabs in a lower quality microhabitat on the reef [36]. Therefore, understanding any influence rhizocephalans may have on the host's spatial distribution, specifically by habitat patch size and distance from the edge, could impact the distribution and survivorship of both the host and parasite, which subsequently may influence local reef dynamics.

To begin understanding how host-parasite relationships are influenced by structured habitat within a marine landscape, the specific objectives of this study were to determine the distribution for (1) oysters and female pea crabs and (2) xanthid crab and rhizocephalans based on seasonality, reef size, and distance from edge to interior. The secondary objective of the study was to determine if carapace width of pea crabs and both parasitized and non-parasitized xanthid crabs varied by season, reef size, and distance from edge to interior, subsequently influencing host-parasite dynamics.

\section{Materials and Methods}

\subsection{Study Sites and Sampling Methods}

A suite of naturally occurring intertidal reefs $(n=22)$ were selected from the coastal, tidal estuaries of Hewletts Creek, Howe Creek, and Masonboro Sound near Wilmington, NC, USA and a complete site description can be found in Hanke et al. [35,36]. Reefs were selected based on natural variation of the distance from the edge to interior of the reef: small ( $3 \mathrm{~m}$ distance to interior, $n=7$ reefs), medium (5-8 $\mathrm{m}$ distance to interior, $n=9$ reefs), and large ( $>14-17 \mathrm{~m}$ distance to interior, $n=6$ reefs).

For two years (2011-2012), reefs were sampled biannually in spring (May-June) and fall (October-December) at distances of $1 \mathrm{~m}$ and $3 \mathrm{~m}$ from the edge of the reef. The medium and large sized reefs were also sampled at the most interior location on the reef (5-8 m for medium and 14-17 $\mathrm{m}$ for large). Oyster densities at each location on the reef were initially sampled with a $0.25 \mathrm{~m}^{2}$ quadrat; however, due to the amount of time and effort spent for this size quadrat during the first sampling period (May-June 2011), the quadrat size was decreased to $0.04 \mathrm{~m}^{2}$ and replicated. The density estimates did not differ between the different quadrat sizes [35]. At the same distances on the reef $(1 \mathrm{~m}, 3 \mathrm{~m}$, and interior locations for large and medium reefs), adult female pea crabs were sampled by hand collecting 20 oysters that measured $50-70 \mathrm{~mm}$ shell height. This sampling approach was utilized to minimize oyster mortality on the reef because the oysters had to be sacrificed to check for a pea crab. This size class of oysters was selected because they were at least a year old, would potentially harbor adult female pea crabs that had survived to adulthood [46,47], and were a common size class on these reefs [35]. Within 24 hours of returning the oysters back to the lab, they were opened and examined for the presence of a female pea crab, and if present, the crab's carapace width was measured. Only females past the first hard stage were included in this study, as males are smaller in comparison (1.4-4.6 mm carapace width) and only parasitize oysters until they reach the first "hard" stage, at which time they leave their host in search of females, mate, and then presumably die [45,46].

Xanthid mud crab collections occurred concurrently, both spatially and temporally, as oyster sampling events. Within a $0.04 \mathrm{~m}^{2}$ quadrat, all shells were removed down to the sediment, returned to the lab, cleaned of mud and debris, and all crabs were removed and preserved in $70 \%$ alcohol. All crabs were then identified and all flatback mud crabs were measured (carapace width in $\mathrm{mm}$ ) and visually inspected for rhizocephalan externae, which was used as a proxy of rhizocephalan prevalence in a host [68]. 


\subsection{Statistical Analysis}

All data was analyzed using SAS Version 9.2 software. When appropriate, all data were tested for homogeneity of variance (Levene's test) prior to running analysis of variance. If the data failed the homogeneity of variance test, the data was transformed $(\log (x+1))$ prior to subsequent analysis. Any significant differences $(p<0.05)$ for ANOVAs were then analyzed with a Student Newman-Keuls post hoc test. Following Baggett et al. [69], all densities are presented as per meter squared.

Variation in oyster densities were log transformed and then tested with a three-way ANOVA by reef size, distance from the reef edge, and season. A chi squared on total counts of pea crabs independently tested for variation in spatial distribution among reef sizes (large, medium, and small) and reef location $(1 \mathrm{~m}, 3 \mathrm{~m}$, and interior). Due to the natural size variation of reefs in the local area, the total number of oysters examined for pea crabs for each sampling period varied among the large $(n=360)$, medium $(n=540)$, and small $(n=280)$ reefs. Additionally, the total number of oysters collected based on distance from the edge of the reef varied between $1 \mathrm{~m}(n=440), 3 \mathrm{~m}(n=440)$, and interior $(n=320)$. To account for these variations, total counts of pea crab were standardized based on equal numbers of oysters collected for either reef size or distance prior to chi-squared analyses. Female pea crab size (carapace width (CW)) was tested with a three-way ANOVA for variation of CW by season, reef size, and distance from edge. Due to the low count of individuals collected at the reef interior $(n=2)$, the distance analysis was only for the $1 \mathrm{~m}$ and 3 m locations.

The densities met homogeneity of variances and separate three-way ANOVAs tested differences by season, reef size, distance from the edge, and season for both parasitized and non-parasitized xanthid crabs. Finally, CW for mud crabs were $\log (x+1)$ transformed prior to analysis. Based upon initial differences of $\mathrm{CW}$ between non-parasitized and parasitized xanthid crabs, separate three-way ANOVAs tested for differences by season, reef size, and distance from reef edge for both non-parasitized and parasitized crabs.

\section{Results}

\subsection{Oysters and Pea Crabs}

Throughout the study, a total of 75 adult female pea crabs were found in 4675 oysters, for an overall incidence of $1.6 \%$. Oyster densities were significantly greater in the fall compared to the spring (Table 1 ); however, pea crab prevalence did not significantly differ between seasons $\left(\chi^{2}=3.75, \mathrm{df}=1, p>0.05\right)$. Large sized reefs had significantly lower oyster densities compared to medium sized reefs (Table 1, Figure 1A), yet female pea crabs had a significantly greater $\left(\chi^{2}=18.07, \mathrm{df}=2, p<0.0001\right)$ utilization of large reefs (Figure 2A). Oyster densities significantly increased from edge to interior reef locations (Table 1, Figure 1B), but pea crab utilization was significantly higher along the reef edge $\left(\chi^{2}=72.23, \mathrm{df}=2, p<0.0001\right.$, Figure $\left.2 \mathrm{~B}\right)$. Only 2 pea crabs were found within the reef interior, with a single individual found within a large and medium sized reef. In the size class (mean $\mathrm{mm} \pm$ S.E.; $62.5 \pm 1.35$ ) of hand collected oysters, the carapace width (CW) of pea crabs showed an interactive effect based on season and reef size (Table 2). Pea crab $\mathrm{CW}$ was significantly smaller $\left(F_{2,41}=4.20, p=0.02\right)$ on large reefs compared to small reefs during the spring; however, in the fall pea crabs were significantly larger on small sized reefs $\left(F_{2,26}=3.83, p=0.03\right)$. 
Table 1. Three-way ANOVA showing the effects of season (fall and spring), reef size (small, medium, and large), and distance from reef edge ( $1 \mathrm{~m}, 3 \mathrm{~m}$, and interior) for oyster (Crassostrea virginica) densities.

\begin{tabular}{lccc}
\hline \multicolumn{1}{c}{ Effects } & df & F Value & $p$ Value \\
\hline Season & 1,220 & 6.05 & $\mathbf{0 . 0 1}$ \\
Size & 2,220 & 4.36 & $\mathbf{0 . 0 1}$ \\
Distance & 2,220 & 29.63 & $<\mathbf{0 . 0 0 0 1}$ \\
Season $\times$ Size & 2,220 & 1.97 & 0.14 \\
Season $\times$ Distance & 2,220 & 0.58 & 0.56 \\
Size $\times$ Distance & 3,220 & 0.57 & 0.63 \\
Season $\times$ Size $\times$ Distance & 3,220 & 0.77 & 0.51 \\
\hline
\end{tabular}

Table 2. Three-way ANOVA showing the effects of season (fall and spring), reef size (small, medium, and large), and distance from reef edge ( $1 \mathrm{~m}, 3 \mathrm{~m}$, and interior) for carapace width of female pea crabs. The distance represents the difference between $1 \mathrm{~m}$ and $3 \mathrm{~m}$ on the reef, as only two females were collected from interior locations on the reef and were subsequently not included in the analysis.

\begin{tabular}{lccc}
\hline \multicolumn{1}{c}{ Effects } & df & F Value & $p$ Value \\
\hline Season & 1,63 & 1.36 & 0.24 \\
Size & 2,63 & 0.97 & 0.38 \\
Distance & 2,63 & 3.32 & 0.07 \\
Season $\times$ Size & 2,63 & 6.02 & $\mathbf{0 . 0 0 4}$ \\
Season $\times$ Distance & 2,63 & 0.76 & 0.38 \\
Size $\times$ Distance & 3,63 & 0.73 & 0.39 \\
Season $\times$ Size $\times$ Distance & 3,63 & 1.76 & 0.18 \\
\hline
\end{tabular}

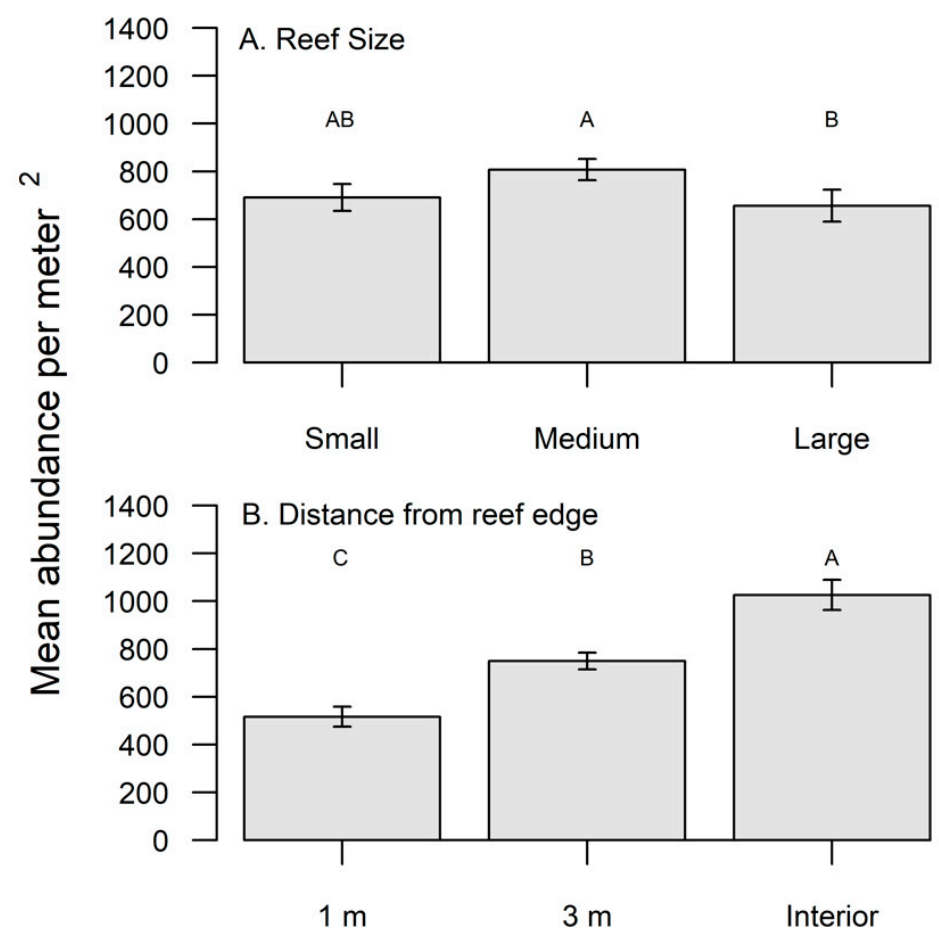

Figure 1. (A) Mean density of oysters per $\mathrm{m}^{2}$ on small, medium, and large reefs and (B) from $1 \mathrm{~m}$, $3 \mathrm{~m}$, and interior locations on the reef. Significant differences in densities were determined with a SNK post hoc test and those that do not share a common superscript are significantly different $(p<0.05)$. 


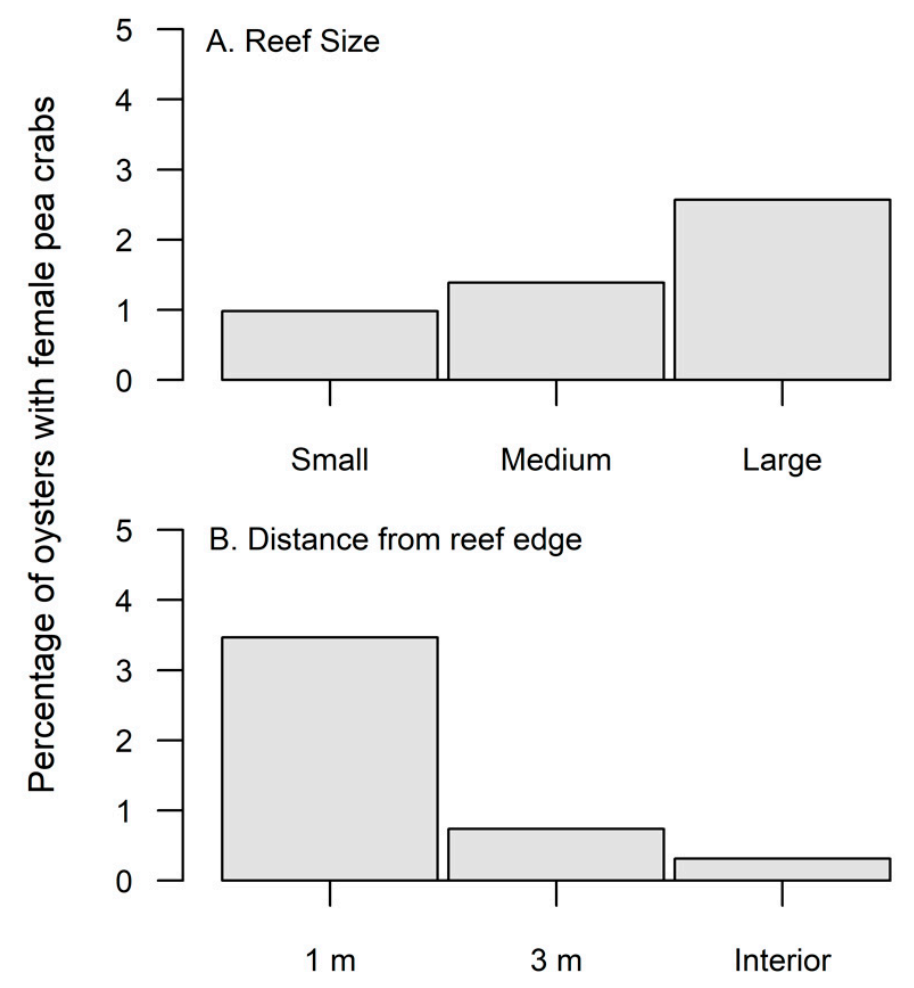

Figure 2. (A) Percentage of oysters on small, medium, and large reefs that contained a female pea crab. Female pea crab utilization was significantly greater $(p<0.0001)$ for large sized reefs. (B) Percentage of oysters from $1 \mathrm{~m}, 3 \mathrm{~m}$, and interior of the reef that contained a pea crab. Female pea crab distribution in the spring was significantly $(p<0.001)$ greater along the edge of the reef.

\subsection{Xanthid Crabs and Rhizocephalans}

A total of 99 out of 427 (23\%) flatback mud crabs collected over the study period had visual indications of being infected by a rhizocephalan. Season did not significantly influence densities for non-parasitized crabs (Table 3A, Figure 3A), but parasitized crabs had significantly greater densities during spring compared to fall (Table 3B, Figure 3A). Reef size had no significant effect on the densities of non-parasitized crabs (Table 3A, Figure 3B) or parasitized crabs (Table 3B, Figure 3B). The reef edge (1 m locations) had significantly lower densities of non-parasitized crabs compared to more interior locations ( $3 \mathrm{~m}$ and interior) (Table $3 \mathrm{~A}$, Figure $3 \mathrm{C}$ ); however, parasitized crabs had no significant edge to interior pattern based on densities (Table 3B, Figure 3C). Yet, the percentage of parasitized crabs was comparatively lower at the reef interior compared to the $1 \mathrm{~m}$ and $3 \mathrm{~m}$ reef locations (Figure 4).

Overall, parasitized crabs were significantly $\left(F_{1,425}=38.21, p<0.0001\right)$ larger (mean $\pm \mathrm{SE} ; 10.04 \pm 0.21 \mathrm{~mm}$, range $4-17 \mathrm{~mm}$ ) compared to non-parasitized crabs (mean $\pm \mathrm{SE}$; $8.16 \pm 0.0 .18 \mathrm{~mm}$, range $4-17 \mathrm{~mm}$ ). Neither season nor reef size significantly influenced the CW of non-parasitized (Table 4A) or parasitized crabs (Table 4B), but the CW of both groups varied significantly based on edge to interior reef locations (Table 4). Non-parasitized xanthid crabs were significantly smaller along the reef edge compared to interior locations (Table 4A, Figure 5), whereas parasitized xanthid crabs had a significantly larger $\mathrm{CW}$ at the $3 \mathrm{~m}$ location compared to other reef locations (Table 4B, Figure 5). 
Table 3. Results of three-way ANOVA for A. non-parasitized flatback xanthid mud crabs (Eurypanopeus depressus) and B. flatback mud crabs parasitized by a parasitic rhizocephalan barnacle (Loxothylacus panopaei) based on densities for season (fall and spring), reef size (small, medium, and large), and distance from reef edge ( $1 \mathrm{~m}, 3 \mathrm{~m}$, and interior).

\begin{tabular}{lccc}
\hline \multicolumn{1}{c}{ Effects } & df & F Value & $p$ Value \\
\hline \multicolumn{1}{c}{ A. Non-parasitized } & & & \\
\hline Season & 1,219 & 0.70 & 0.40 \\
Size & 2,219 & 0.32 & 0.72 \\
Distance & 2,219 & 9.34 & $\mathbf{0 . 0 0 0 1}$ \\
Season $\times$ Size & 2,219 & 2.37 & 0.09 \\
Season $\times$ Distance & 2,219 & 0.63 & 0.53 \\
Size $\times$ Distance & 3,219 & 0.50 & 0.68 \\
Season $\times$ Size $\times$ Distance & 3,219 & 0.55 & 0.64 \\
\hline \multicolumn{1}{c}{ B. Parasitized } & & & \\
\hline Season & 1,219 & 20.38 & 0.0001 \\
Size & 2,219 & 0.53 & 0.31 \\
Distance & 2,219 & 1.17 & 0.65 \\
Season $\times$ Size & 2,219 & 0.42 & 0.50 \\
Season $\times$ Distance & 2,219 & 0.68 & 0.89 \\
Size $\times$ Distance & 3,219 & 0.20 & 0.90 \\
Season $\times$ Size $\times$ Distance & 3,219 & 0.18 & \\
\hline
\end{tabular}

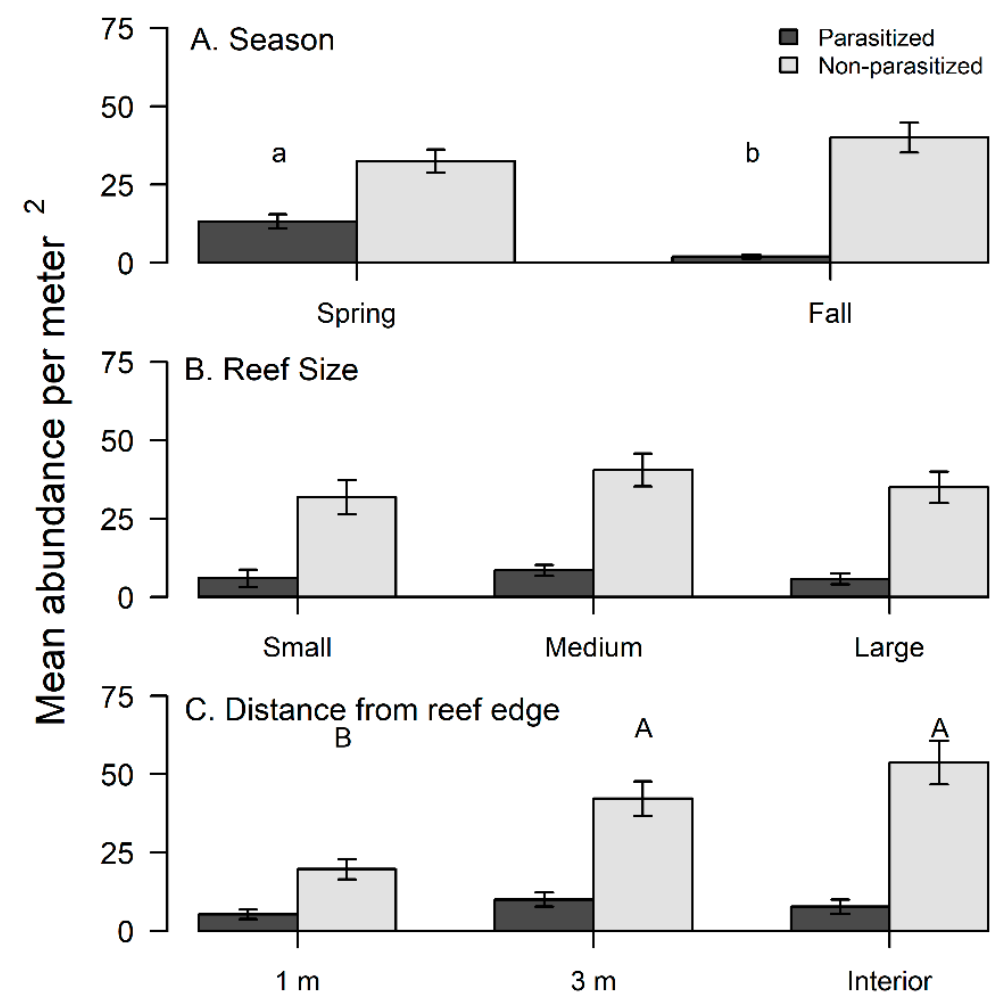

Figure 3. Differences in densities of non-parasitized flatback xanthid mud crabs (Eurypanopeus depressus) and flatback mud crabs parasitized by a parasitic rhizocephalan barnacle (Loxothylacus panopaei) based on (A) season, (B) reef size, and (C) distance from reef edge. Significant differences in densities were determined with a SNK post hoc test and those that do not share a common superscript (capitalized for non-parasitized xanthid crabs and lower case for parasitized) are significantly different $(p<0.05)$. 


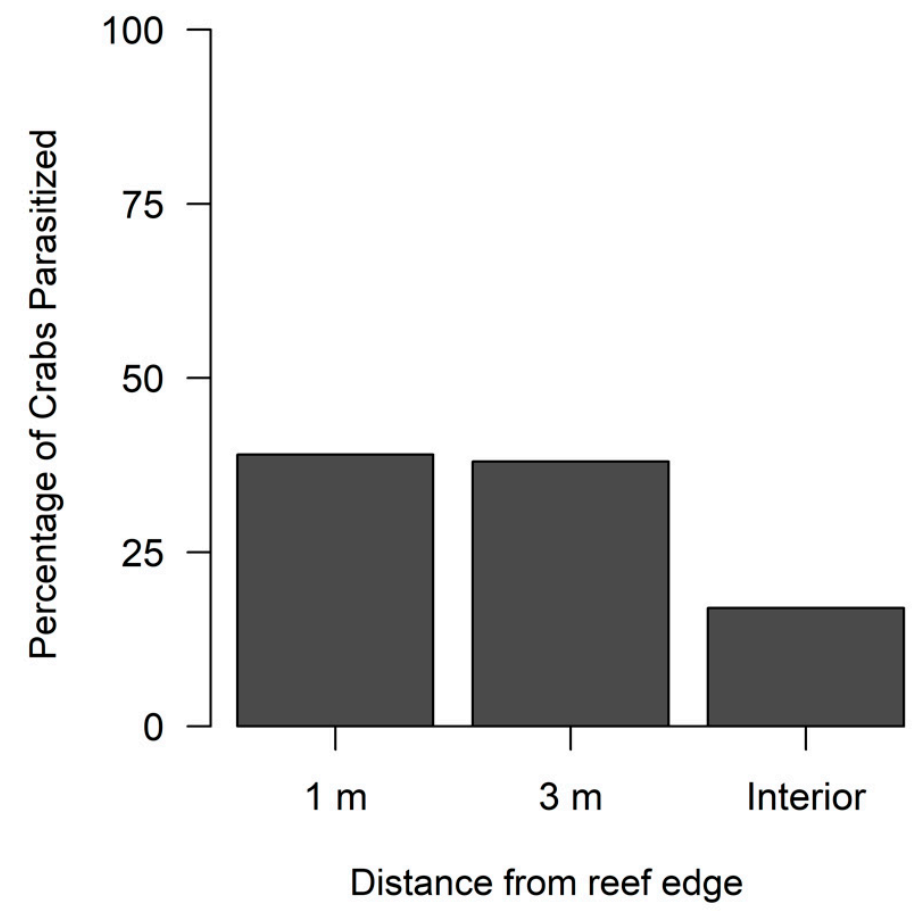

Figure 4. Percentage of flatback xanthid mud crabs (Eurypanopeus depressus) parasitized by a parasitic rhizocephalan barnacle (Loxothylacus panopaei) at each distance from the reef edge. Interior locations are 5-8 $\mathrm{m}$ for medium sized reefs and $14-17 \mathrm{~m}$ for large sized reefs from the reef edge.

Table 4. Three-way ANOVA for variation in carapace width of A. non-parasitized flatback xanthid mud crabs (Eurypoanopeus depressus) and B. flatback mud crabs parasitized by a parasitic rhizocephalan barnacle (Loxothylacus panopaei) based on season (fall and spring), reef size (small, medium, and large), and distance from reef edge ( $1 \mathrm{~m}, 3 \mathrm{~m}$, and interior).

\begin{tabular}{lccc}
\hline \multicolumn{1}{c}{ Effects } & df & F Value & $p$ Value \\
\hline \multicolumn{1}{c}{ A. Non-parasitized } & & & \\
\hline Season & 1,312 & 0.01 & 0.92 \\
Size & 2,312 & 1.47 & 0.23 \\
Distance & 2,312 & 3.22 & $\mathbf{0 . 0 4}$ \\
Season $\times$ Size & 2,312 & 0.98 & 0.37 \\
Season $\times$ Distance & 2,312 & 0.02 & 0.98 \\
Size $\times$ Distance & 2,312 & 0.32 & 0.80 \\
Season $\times$ Size $\times$ Distance & 3,312 & 1.01 & 0.39 \\
\hline$\quad$ B. Parasitized & & & \\
\hline Season & 1,89 & 0.18 & 0.67 \\
Size & 2,89 & 0.03 & 0.97 \\
Distance & 2,89 & 6.49 & 0.022 \\
Season $\times$ Size & 2,89 & 1.52 & 0.60 \\
Season $\times$ Distance & 2,89 & 0.51 & 0.22 \\
Size $\times$ Distance & 2,89 & 1.50 & 0.70 \\
Season $\times$ Size $\times$ Distance & 3,89 & 0.47 & \\
\hline
\end{tabular}




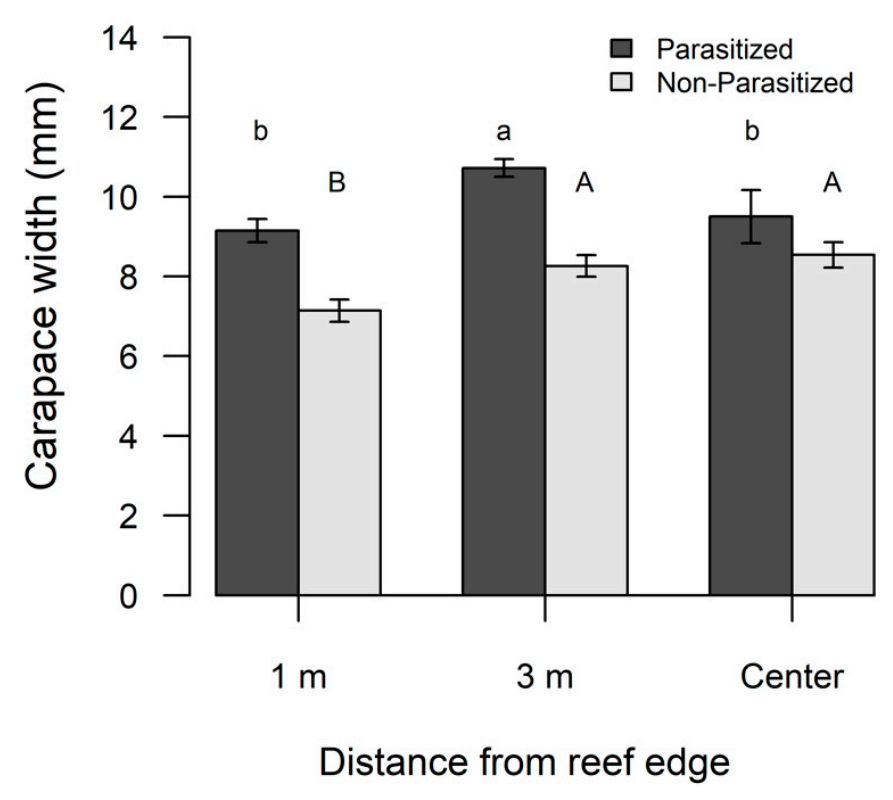

Figure 5. Differences in carapace width (CW) for non-parasitized flatback xanthid mud crabs (Eurypanopeus depressus) and flatback mud crabs parasitized by a parasitic rhizocephalan barnacle (Loxothylacus panopaei). Significant differences in CW were determined with a SNK post hoc test and those that do not share a common superscript (capitalized for non-parasitized xanthid crabs and lower case for parasitized) are significantly different $(p<0.05)$.

\section{Discussion}

The spatial distribution of hosts and parasites examined in this study suggests that host-parasite relationships on intertidal oyster reefs are influenced by habitat characteristics, but the response is specific to the individual species and the host-parasite relationship. Seasonal effects were observed within both host-parasite relationships but demonstrated opposite patterns in terms of differences for the host or the parasite. Oyster densities were significantly greater in the fall but pea crab prevalence did not significantly differ between the seasons, while non-parasitized xanthid crabs had no seasonal effect, but densities of parasite crabs were significantly greater in the spring. There was variation in the response to habitat patch size, as oysters had lower densities on large sized reefs, while pea crabs had the greatest prevalence on this size class of reefs. However, non-parasitized and parasitized xanthids demonstrated no patch size effect for densities. Edge effects had the strongest impact on the population dynamics of these host-parasite relationships. Oyster densities significantly increased towards the reef interior, while female pea crabs had the highest prevalence on the reef edges. Non-parasitized xanthid crabs had significantly lower densities, and smaller sized crabs along the reef edges, while parasitized crabs had no significant pattern for density between edge and interior locations but parasitized crabs were significantly larger at $3 \mathrm{~m}$ from the reef edge.

Overall, species in both host-parasite relationships demonstrated seasonal effects but varied between the hosts and parasites. First, oyster densities exhibited a strong seasonal pattern, with greater densities in the fall compared to the spring. This result is unsurprising, as the fall sampling captured the influx of new recruits to the reef over the spawning season (May-October) [35]. However, pea crab counts were not significantly different between season, which is most likely attributed to the sampling regime. Pea crabs preferentially recruit to oyster spat $[46,70]$ and, within the study region, it has been suggested pea crabs have a synchronized spawning period with oyster recruitment [47]. Therefore, the lack of seasonal differences for pea crabs may be a result of only examining oysters that were $50-70 \mathrm{~mm}$, as these oysters would only be harboring pea crabs that survived long enough for the oysters, and subsequentially the pea crabs, to recruit into the sampled size class. Limited seasonal effects were also found for xanthid crabs and the rhizocephalan. 
No temporal variation was found for densities of non-parasitized crabs, yet parasitized xanthids had significantly greater densities during spring. The greater numbers of crabs having an externae in the spring may be a strategy for the rhizocephalan to increase the ability of their larvae to infect a host. Planktonic rhizocephalan have been suggested to settle on, and infect, smaller crabs because they molt more frequently. Therefore, it appears the parasite has likely synchronized reproduction with its host, as the peak time for gravid xanthid females is April-May [55,71].

The strong spatial pattern of female pea crabs occurring primarily on large and medium sized reefs indicates that habitat patchiness influences their habitat distribution and, more importantly survivorship [47]. The greater number of female pea crabs on the large reefs, despite lower oyster abundances on the large sized reefs, could be attributed to post-settlement processes for pea crabs. Densities of oyster spat have been experimentally demonstrated to not influence the proportion of infested of pea crabs [47], suggesting pea crabs may not select reefs based on host densities. The greater number of observed pea crabs on the medium and large reefs may be a result of the relationship between patch size and the amount of edge. With increasing size, the reefs would have greater total area of edge habitat, but overall lower ratio of edge to interior area, for female recruitment and potentially increasing the reproductive success by increasing the chance of a male encountering a female within an oyster. The failure to detect a response from both parasitized and non-parasitized xanthids to varied patch sizes, at least for the sizes examined in this study, further highlights the importance of the species level response to habitat patchiness. Although, it may be that this host-parasite relationship did not respond to the reef sizes examined in this study because the minimum habitat patch size threshold for persistence is smaller than the reefs used in this study.

Edge and interior habitats have been demonstrated to be an important landscape factor for host-parasite relationships in terrestrial habitats $[11,25,26]$ and both host-parasite relationships demonstrated edge effects in some fashion, indicating spatial location within habitat patches can also influence marine host-parasite relationships. Oyster densities increased towards the reef interior and female pea crab's prevalence was greatest along edges. This interesting pattern may be a result of recruitment processes for both organisms and other ecological interactions, specifically predation. Greater prevalence of female pea crabs in edges habitats may be attributed to their preferential recruitment based on tidal variation on reefs. This was suggested by Beach (1969) when he observed the greatest number of pea crabs at the low tide mark and the lowest number in the high tide area. A recent study by Carroll et al. [72] also found the greatest pea crab recruitment in the lower intertidal zone, further suggesting host acquisition for pea crabs would be greatest along the reef edges because it is the first area inundated by an incoming tide. Preferential recruitment of pea crabs to reef edges may further be attributed to the larvae preferentially recruiting to oyster spat $[46,47,50]$. In southeastern North Carolina, $22-27 \%$ of oyster spat were found to have at least one pea crab present [47], but this number can be as high as approximately $35 \%$ [50]. Oyster recruitment is highest within the first $3 \mathrm{~m}$ of the reef [35], facilitating increased pea crab settlement within the reef edge. However, oyster spat survivorship is low along the reef edges [35], as intertidal reef edges are heavily foraged by predators compared to the interior [41]. The presence of a pea crab could potentially decrease predation on spat because pea crabs have been suggested to have a chemical defense to deter predators [73], thus leading to increased survivorship for parasitized oyster spat along the reef edge.

Edge to interior patterns varied between non-parasitized and parasitized xanthid crabs, suggesting rhizocephalans may impact their hosts intrapatch spatial distribution. Non-parasitized xanthids had significantly lower densities along reef edges compared to more interior locations, likely a function of preferential utilization of habitat structure. Meyer [61] found flatback mud crabs had a positive association with increased shell cover and oyster shell culm volume, which they were utilizing for refuge. Intertidal reef edges have less shell cover and three dimensional structure compared to interior locations [35], 
therefore, these non-parasitized xanthid densities are likely lower along edges due to some combination of limited habitat structure and increased predation risk [32,41,74]. This may explain why non-parasitized crabs were smaller along edges compared to interior locations, as smaller individuals can utilize the limited reef structure along the reef edge until they reach a threshold of body size and become increasingly vulnerable to predation. Whereas non-parasitized crabs utilizing more interior locations, which have increased reef structure compared to the edge [35], would have greater predator refuge and food resources, potentially leading to increased overall size. Parasitized crabs, interestingly, had no significant differences for density between edge and interior locations and had a higher proportion of parasitism within the first three meters of the reef compared to interior locations. Previous work with mesocosms suggests that parasitized xanthid crabs should experience higher rates of predation within the edge habitat, leading to lower comparative densities and proportions of parasitized crabs. First, Gehman and Byers [75] experimentally found that parasitized xanthid crabs were preferentially preyed upon compared to non-parasitized crabs. Further, Brothers and Blakeslee [56] experimentally found that parasitized xanthids were completely preyed upon in habitats of low complexity, but had similar predation rates as non-parasitized xanthids in complex habitats. These previous experiments suggest parasitized xanthid crabs should have a similar edge to interior pattern as non-parasitized xanthids and the deviation from this pattern may be a result of several mechanisms. First, parasitized xanthid crabs have depressed activity levels and lower foraging rates compared to non-parasitized crabs [57,60], potentially decreasing predation risk along reef edges if parasitized crabs have not been actively foraging as often. Second, parasitized crabs have greater vagility compared to non-parasitized crabs [75], which potentially offers parasitized xanthid crabs a marginally greater chance to escape predation within the heavily foraged reef edge [41].

It is also important to note that parasitized xanthid crabs were significantly larger overall compared to non-parasitized crabs. This is surprising considering rhizocephalan infections can limit host growth [55]. The greater CW of parasitized xanthids could be a result of smaller sized crabs not having signs of infection, even though the size range of parasitized crabs found in this study was similar to the size range of parasitized crabs in other studies, or the externae simply had fallen off $[51,55,57,60]$. Takahashi and Matsuura [76] observed a positive size-prevalence pattern for shore crabs (Hemigrapsus sanguineus) parasitized by a rhizocephalan (Sacculina senta) and due to the crabs having shed the externae, molted to a larger size, and then the parasite regenerated a new externae. If molting continues while parasitized, then the spatial patterns of significantly larger parasitized crabs observed at $3 \mathrm{~m}$ from the reef edge suggest that there may be spatial heterogeneity in growth or survivorship of parasitized crabs, with this microhabitat functioning as an optimal habitat for growth of the between the edge and most interior microhabitats.

Oyster reefs have become highly fragmented within the last century due to various factors, such as over harvesting, eutrophication, disease, and many other anthropogenic disturbances $[38,39,77]$. This habitat loss and fragmentation appears to also have an impact on spatial dynamics host-parasite relationships within this marine habitat type. The high spatial variability of the hosts and parasites observed suggests future alteration and fragmentation of habitat patches may become more impactful on host-parasite relationships and local patch dynamics. Given the great spatial variability of these parasitic interactions within microhabitats, the composition and configuration of local habitat patches may be contributing to the high regional variability observed for these two host-parasite relationships $[50,53,66]$. For example, both host-parasite interactions demonstrated an edge effect; however, the response was very different. This suggests that species interactions, based on the marine landscape, should be considered independently. Finally, this study highlights that future preservation and restoration efforts of marine habitats should consider the spatial context of habitat patches, as preservation or creation of specific microhabitats can impact both host and parasite populations. 
Author Contributions: Conceptualization, M.H.H., M.H.P. and T.D.A.; methodology, M.H.H., M.H.P. and T.D.A.; software, M.H.H., M.H.P. and T.D.A.; validation, M.H.H., M.H.P. and T.D.A.; formal analysis, M.H.H., M.H.P. and T.D.A.; investigation, M.H.H.; resources, M.H.H., M.H.P. and T.D.A.; data curation, M.H.H., M.H.P. and T.D.A.; writing-original draft preparation, M.H.H.; writingreview and editing, M.H.H., M.H.P. and T.D.A.; visualization, M.H.H.; supervision, M.H.P. and T.D.A.; project administration, M.H.H., M.H.P. and T.D.A.; funding acquisition, M.H.P. and T.D.A. All authors have read and agreed to the published version of the manuscript.

Funding: This research was partially funded by North Carolina Sea Grant, American Recovery and Reinvestment Act (ARRA), North Carolina Coastal Recreational Fishing License (CRFL) Grant, and the Kenan Creek Project.

Institutional Review Board Statement: Not applicable.

Data Availability Statement: Data is available from the corresponding author upon request.

Acknowledgments: We would like to thank the many individuals from the UNCW Benthic lab that helped in field sampling. We would also like to thank J Wilson White, Zachary Long, and David Meyer for insightful comments that greatly improved this manuscript. Finally, we thank the reviewers for helpful comments that greatly improved this manuscript.

Conflicts of Interest: The authors declare no conflict of interest.

\section{References}

1. Fagan, W.F.; Cantrell, R.S.; Cosner, C. How habitat edges change species interactions. Am. Nat. 1999, 153, 165-182. [CrossRef] [PubMed]

2. Tews, J.; Brose, U.; Grimm, V.; Tielbörger, K.; Wichmann, M.C.; Schwager, M.; Jeltsch, F. Animal species diversity driven by habitat heterogeneity/diversity: The importance of keystone structures. J. Biogeogr. 2004, 31, 79-92. [CrossRef]

3. Loreau, M.; Naeem, S.; Inchausti, P.; Bengtsson, J.; Grime, J.P.; Hector, A.; Hooper, D.U.; Huston, M.; Raffaelli, D.; Schmid, B.; et al. Biodiversity and ecosystem functioning: Current knowledge and future challenges. Science 2001, 294, 804-808. [CrossRef] [PubMed]

4. Tscharntke, T.; Tylianakis, J. Landscape moderation of biodiversity patterns and processes-eight hypotheses. Biol. Rev. 2012, 87, 661-685. [CrossRef]

5. Fahrig, L. Rethinking patch size and isolation effects: The habitat amount hypothesis. J. Biogeogr. 2013, 40, 1649-1663. [CrossRef]

6. Holyoak, M. Habitat patch arrangement and metapopulation persistence of predators and prey. Am. Nat. 2000, 156, 378-389. [CrossRef]

7. Martinson, H.; Fagan, W.; Denno, R. Critical patch sizes for food-web modules. Ecology 2012, 93, 1779-1786. [CrossRef]

8. Ewers, R.; Thorpe, S.; Didham, R. Synergistic interactions between edge and area effects in a heavily fragmented landscape. Ecology 2007, 88, 96-106. [CrossRef]

9. Thomas, C.D. Dispersal and extinction in fragmented landscapes. Proc. R. Soc. B Biol. Sci. 2000, 267, 139-145. [CrossRef]

10. Haila, Y. A conceptual genealogoy of fragmentation research: From island biogeography to landscape ecology. Ecol. Appl. 2002, 12, 321-334.

11. Cronin, J.T. Habitat edges, within-patch dispersion of hosts, and parasitoid oviposition behavior. Ecology 2009, 90, 196-207. [CrossRef]

12. Hussain, S.; Ram, M.S.; Kumar, A.; Shivaji, S.; Umapathy, G. Human presence increases parasitic load in endangered lion-tailed macaques (Macaca silenus) in its fragmented rainforest habitats in Southern India. PLoS ONE 2013, 8, e63685. [CrossRef]

13. Pullan, R.L.; Sturrock, H.J.; Soares Magalhães, R.J.; Clements, A.C.; Brooker, S.J. Spatial parasite ecology and epidemiology: A review of methods and applications. Parasitology 2012, 139, 1870-1887. [CrossRef]

14. Arneberg, P.; Skorping, A.; Grenfell, B.; Read, A.F. Host densities as determinant of abundance in parasite communities. Proc. R. Soc. B Biological Sci. 1998, 265, 1283-1289. [CrossRef]

15. Ryder, J.J.; Miller, M.R.; White, A.; Knell, R.J.; Boots, M. Host-parasite population dynamics under combined frequency- and density-dependent transmission. Oikos 2007, 116, 2017-2026. [CrossRef]

16. Stiling, P.D. The frequency of density dependence in insect host-parasitoid systems. Ecology 1987, 68, 844-856. [CrossRef]

17. Mbora, D.N.M.; McPeek, M.A. Host density and human activities mediate increased parasite prevalence and richness in primates threatened by habitat loss and fragmentation. J. Anim. Ecol. 2009, 78, 210-218. [CrossRef]

18. Fahrig, L.; Paloheimo, J. Effect of Spatial Arrangement of Habitat Patches on Local Population Size. Ecology 1988, 69, 468-475. [CrossRef]

19. Fahrig, L. Effects of habitat fragmentaion on biodiversity. Annu. Rev. Ecol. Evol. Syst. 2003, 34, 487-515. [CrossRef]

20. Sullivan, L.L.; Johnson, B.L.; Brudvig, L.A.; Haddad, N.M. Can dispersal mode predict corridor effects on plant parasites? Ecology 2011, 92, 1559-1564. [CrossRef] 
21. Bordes, F.; Morand, S.; Pilosof, S.; Claude, J.; Krasnov, B.R.; Cosson, J.F.; Chaval, Y.; Ribas, A.; Chaisiri, K.; Blasdell, K.; et al. Habitat fragmentation alters the properties of a host-parasite network: Rodents and their helminths in South-East Asia. J. Anim. Ecol. 2015, 84, 1253-1263. [CrossRef] [PubMed]

22. Lopez, J.E.; Gallinot, L.P.; Wade, M.J. Spread of parasites in metapopulations: An experimental study of the effects of host migration rate and local host population size. Parasitology 2005, 130, 323-332. [CrossRef] [PubMed]

23. Renwick, A.R.; Lambin, X. Host-parasite interactions in a fragmented landscape. Int. J. Parasitol. 2013, 43, 27-35. [CrossRef] [PubMed]

24. Lloyd-Smith, J.O.; Cross, P.C.; Briggs, C.J.; Daugherty, M.; Getz, W.M.; Latto, J.; Sanchez, M.S.; Smith, A.B.; Swei, A. Should we expect population thresholds for wildlife disease? Trends Ecol. Evol. 2005, 20, 511-519. [CrossRef]

25. Ries, L.; Fletcher Jr, R.; Battin, J.; Sisk, T.D. Ecological response to habitat edges: Mechanisms, models, and variability explained. Annu. Rev. Ecol. Evol. Syst. 2004, 35, 491-522. [CrossRef]

26. Gates, J.E.; Gysel, L.W. Avian nest dispersion and fledging success in field-forest ecotones. Ecology 1978, 59, 871-883. [CrossRef]

27. Patten, M.; Shochat, E.; Reinking, D.L.; Wolfe, D.H.; Sherrod, S.K. Habitat edge, land management, and rates of brood parasitism in tallgrass prairie. Ecol. Appl. 2006, 16, 687-695. [CrossRef]

28. Donovan, T.; Jones, P.; Annand, E.; Thompson, F.T., III. Variation in local-scale edge effects: Mechanisms and landscape context. Ecology 1997, 78, 2064-2075. [CrossRef]

29. Ries, L.; Sisk, T. A predictive model of edge effects. Ecology 2004, 85, 2917-2926. [CrossRef]

30. Peterson, M.S.; Andres, M.J. Progress on Research Regarding Ecology and Biodiversity of Coastal Fisheries and Nektonic Species and Their Habitats within Coastal Landscapes. Diversity 2021, 13, 168. [CrossRef]

31. Meyer, D.L.; Townsend, E.C. Faunal utilization of created intertidal eastern oyster (Crassostrea virginica) reefs in the southeastern United States. Estuaries 2000, 23, 34-45. [CrossRef]

32. Grabowski, J.; Powers, S. Habitat complexity mitigates trophic transfer on oyster reefs. Mar. Ecol. Prog. Ser. 2004, 277, 291-295. [CrossRef]

33. Peterson, C.; Grabowski, J.; Powers, S. Estimated enhancement of fish production resulting from restoring oyster reef habitat: Quantitative valuation. Mar. Ecol. Prog. Ser. 2003, 264, 249-264. [CrossRef]

34. Coen, L.; Brumbaugh, R.; Bushek, D.; Grizzle, R.; Luckenbach, M.; Posey, M.; Powers, S.; Tolley, S. Ecosystem services related to oyster restoration. Mar. Ecol. Prog. Ser. 2007, 341, 303-307. [CrossRef]

35. Hanke, M.H.; Posey, M.H.; Alphin, T.D. The influence of habitat characteristics on intertidal oyster Crassostrea virginica populations. Mar. Ecol. Prog. Ser. 2017, 571, 121-138. [CrossRef]

36. Hanke, M.H.; Posey, M.H.; Alphin, T.D. The effects of intertidal oyster reef habitat characteristics on faunal utilization. Mar. Ecol. Prog. Ser. 2017, 581, 57-70. [CrossRef]

37. Lenihan, H.; Peterson, C. How habitat degradation through fishery disturbance enhances impacts of hypoxia on oyster reefs. Ecol. Appl. 1998, 8, 128-140. [CrossRef]

38. Coen, L.D.; Luckenbach, M.W. Developing success criteria and goals for evaluating oyster reef restoration: Ecological function or resource exploitation? Ecol. Eng. 2000, 15, 323-343. [CrossRef]

39. Beck, M.W.; Brumbaugh, R.D.; Airoldi, L.; Carranza, A.; Coen, L.D.; Crawford, C.; Defeo, O.; Edgar, G.J.; Hancock, B.; Kay, M.C.; et al. Oyster reefs at risk and recommendations for conservation, restoration, and management. Bioscience 2011, 61, 107-116. [CrossRef]

40. Harwell, H.D.; Posey, M.H.; Alphin, T.D. Landscape aspects of oyster reefs: Effects of fragmentation on habitat utilization. J. Exp. Mar. Bio. Ecol. 2011, 409, 30-41. [CrossRef]

41. Macreadie, P.; Geraldi, N.; Peterson, C. Preference for feeding at habitat edges declines among juvenile blue crabs as oyster reef patchiness increases and predation risk grows. Mar. Ecol. Prog. Ser. 2012, 466, 145-153. [CrossRef]

42. Eggleston, D.B.; Etherington, L.L.; Elis, W.E. Organism response to habitat patchiness: Species and habitat-dependent recruitment of decapod crustaceans. J. Exp. Mar. Bio. Ecol. 1998, 223, 111-132. [CrossRef]

43. Eggleston, D.B.; Elis, W.E.; Etherington, L.L.; Dahlgren, C.P.; Posey, M.H. Organism responses to habitat fragmentation and diversity: Habitat colonization by estuarine macrofauna. J. Exp. Mar. Bio. Ecol. 1999, 236, 107-132. [CrossRef]

44. Griffitt, J.; Posey, M.H.; Alphin, T.D. Effects of edge fragmentation on oyster reef utilization by transient nekton. J. Elisha Mitchell Sci. Soc. 1999, 115, 98-103.

45. Stauber, L. Pinnotheres ostreum, parasitic on the American oyster, Ostrea (Gryphaea) virginica. Biol. Bull. 1945, 88, 269-291. [CrossRef]

46. Christensen, A.; McDermott, J. Life-history and biology of the oyster crab, Pinnotheres ostreum Say. Biol. Bull. 1958, 114, 146-179. [CrossRef]

47. Hanke, M.H.; Hargrove, J.M.; Alphin, T.D.; Posey, M.H. Oyster utilization and host variation of the oyster pea crab (Zaops ostreum). J. Shellfish Res. 2015, 34, 281-287. [CrossRef]

48. Haven, D. The pea crab Pinnotheres ostreum as a parasite of the oyster. Va. J. Sci. 1958, 8, 301-302.

49. Mercado-Silva, N. Condition index of the eastern oyster, Crassostrea virginica (Gmelin, 1791) in Sapelo Island Georgia-Effects of site, position on bed and pea crab parasitism. J. Shellfish Res. 2005, 24, 121-126.

50. Byers, J.E.; Rogers, T.L.; Grabowski, J.H.; Hughes, R.A.; Piehler, M.F.; Kimbro, D.L. Host and parasite recruitment correlated at a regional scale. Oecologia 2014, 174, 731-738. [CrossRef] 
51. Hines, A.; Alvarez, F.; Reed, S. Introduced and native populations of a marine parasitic castrator: Variation in prevalence of the rhizocephalan Loxothylacus panopaei in xanthid crabs. Bull. Mar. Sci. 1997, 61, 197-214.

52. Tolley, S.G.; Winstead, J.T.; Haynes, L.; Volety, A.K. Influence of salinity on prevalence of the parasite Loxothylacus panopaei in the xanthid Panopeus obesus in SW Florida. Dis. Aquat. Organ. 2006, 70, 243-250. [CrossRef] [PubMed]

53. Freeman, A.; Blakeslee, A.; Fowler, A. Northward expansion of the rhizocephalan Loxothylacus panopaei (Gissler, 1884) in the northwest Atlantic. Aquat. Invasions 2013, 8, 347-353. [CrossRef]

54. Kruse, I.; Hare, M.P.; Hines, A.H. Genetic relationships of the marine invasive crab parasite Loxothylacus panopaei: An analysis of DNA sequence variation, host specificity, and distributional range. Biol. Invasions 2011, 14, 701-715. [CrossRef]

55. Alvarez, F.; Hines, A.H.; Reaka-kudla, M.L. The effects of parasitism by the barnacle Loxothylacus panopaei (Gissler) (Cirripedia: Rhizocephala) on growth and survival of the host crab Rhithropanopeus harrisii (Gould) (Brachyura: Xanthidae). J. Exp. Mar. Bio. Ecol. 1995, 192, 221-232. [CrossRef]

56. Brothers, C.A.; Blakeslee, A.M.H. Alien vs predator play hide and seek: How habitat complexity alters parasite mediated host survival. J. Exp. Mar. Bio. Ecol. 2021, 535, 151488. [CrossRef]

57. O'Shaughnessy, K.A.; Harding, J.M.; Burge, E.J. Ecological effects of the invasive parasite Loxothylacus panopaei on the flatback mud crab Eurypanopeus depressus with implications for estuarine communities. Bull. Mar. Sci. 2014, 90, 611-621. [CrossRef]

58. Grosholz, E.D.; Ruiz, G.M. Does spatial heterogeneity and genetic variation in populations of the xanthid crab Rhithropanopeus harrisii (Gould) influence the prevalence of an introduced parasitic castrator? J. Exp. Mar. Bio. Ecol. 1995, 187, 129-145. [CrossRef]

59. Kulp, R.; Politano, V.; Lane, H. Predation of juvenile Crassostrea virginica by two species of mud crabs found in the Chesapeake Bay. J. Shellfish Res. 2011, 30, 1-6. [CrossRef]

60. Toscano, B.J.; Newsome, B.; Griffen, B.D. Parasite modification of predator functional response. Oecologia 2014, 175, 345-352. [CrossRef]

61. Meyer, D.L. Habitat partitioning between the Xanthid crabs Panopeus herbstii and Eurypanopeus depressus on intertidal oyster reefs (Crassostrea virginica) in southeastern North Carolina. Estuaries 1994, 17, 674-679. [CrossRef]

62. Silliman, B.R.; Layman, C.A.; Geyer, K.; Zieman, J.C. Predation by the black-clawed mud crab, Panopeus herbstii, in Mid-Atlantic salt marshes: Further evidence for top-down control of marsh grass production. Estuaries 2004, 27, 188-196. [CrossRef]

63. Robinson, E.; Lunt, J.; Marshall, C.; Smee, D. Eastern oysters Crassostrea virginica deter crab predators by altering their morphology in response to crab cues. Aquat. Biol. 2014, 20, 111-118. [CrossRef]

64. Toscano, B.; Griffen, B. Predatory crab size diversity and bivalve consumption in oyster reefs. Mar. Ecol. Prog. Ser. 2012, 445, 65-74. [CrossRef]

65. Grabowski, J. Habitat complexity disrupts predator-prey interactions but not the trophic cascade on oyster reefs. Ecology 2004, 85, 995-1004. [CrossRef]

66. Kruse, I.; Hare, M.P. Genetic diversity and expanding nonindigenous range of the rhizocephalan Loxothylacus panopaei parasitizing mud crabs in the western north Atlantic. J. Parasitol. 2007, 93, 575-582. [CrossRef]

67. Glancy, T.; Frazer, T.; Cichra, C.; Lindberg, W. Comparative patterns of occupancy by decapod crustaceans in seagrass, oyster, and marsh-edge habitats in a northeast Gulf of Mexico estuary. Estuaries 2003, 26, 1291-1301. [CrossRef]

68. Sloan, L.M.; Anderson, S.V.; Pernet, B. Kilometer-scale spatial variation in revalence of the rhizocephalan Lernaeodiscus porcellanae on the Porcelain Crab Petrolisthes cabrilloi. J. Crustac. Biol. 2010, 30, 159-166. [CrossRef]

69. Baggett, L.P.; Powers, S.P.; Brumbaugh, R.; Coen, L.D.; DeAngelis, B.; Greene, J.; Hancock, B.; Morlock, S. Oyster Habitat Restoration Monitoring and Assessment Handbook; The Nature Conservancy: Arlington, VA, USA, 2014; 96p.

70. Kimbro, D.L.; Byers, J.E.; Grabowski, J.H.; Hughes, A.R.; Piehler, M.F. The biogeography of trophic cascades on US oyster reefs. Ecol. Lett. 2014, 17, 845-854. [CrossRef]

71. McDonald, J. Divergent life history patterns in the po-occuring intertidal crabs Panopeus herbstii and Eurypanopeus depressus (Crustacea: Brachyura: Xanthidae). Mar. Ecol. Prog. Ser. 1982, 8, 173-180. [CrossRef]

72. Carroll, J.M.; Dashiell, R.; Watts, J.C.; Hunter, E.A. Tidal level affects the prevalence and impacts of pests and parasites on oysters (Crassostrea virginica) on intertidal reefs in Georgia, USA. Mar. Biol. 2021, 168, 1-11. [CrossRef]

73. Luckenbach, M.W.; Orth, R. A chemical defense in Crustacea? J. Exp. Mar. Bio. Ecol. 1990, 137, 79-87. [CrossRef]

74. Hill, J.; Weissburg, M. Habitat complexity and predator size mediate interactions between intraguild blue crab predators and mud crab prey in oyster reefs. Mar. Ecol. Prog. Ser. 2013, 488, 209-219. [CrossRef]

75. Gehman, A.L.M.; Byers, J.E. Non-native parasite enhances susceptibility of host to native predators. Oecologia 2017, 183, 919-926. [CrossRef]

76. Takahashi, T.; Matsuura, S. Laboratory studies on molting and growth of the shore crab, Hemigrapsus sanguineus de Haan, parasitized by a rhizocephalan barnacle. Biol. Bull. 1994, 300-308. [CrossRef]

77. Kennedy, V.S.; Breisch, L.L. Sixteen decades of polical management of the oyster fishery in Maryland's Chesapeake Bay. J. Environ. Manag. 1983, 164, 153-171. 